Nau Literária: crítica e teoria de literaturas

www.seer.ufrgs.br/nauliteraria

ISSN 1981-4526 - PPG-LET-UFRGS - Porto Alegre

Vol. 11 N. 02

Literatura e Guerra

BITTENCOURT, Rita Lenira de Freitas. Guerra e Poesia:

Dispositivos Bélico-Poéticos do Modernismo. Porto Alegre:

UFRGS, 2014.

\title{
A PÓlVORA E O PIGMENTO
}

André Winter Noble ${ }^{1}$

Do Prata ao ouro, ou de volta à prata. Há, nesta frase, uma sutil menção à chacina do Paraguai (ou guerra), conflito que, aqui, se fez frase desde Guerra e Poesia: Dispositivos Bélico-Poéticos do Modernismo (2014), livro assinado pela professora, teórica e crítica literária Rita Lenira de Freitas Bittencourt. Nessa obra, a autora debruça-se sobre o modernismo latinamericano, tendo o conflito bélico (e de vaidades) como pano de fundo. Lona esta da qual emergem figuras caquéticas com seus rufos futuristas, babados de aço e balões discursivos facilmente associados aos primeiros nacionalismos (Estados Nacionais) e ainda outras personas, às margens do cenário, com feições mestiças, falas mescladas, metralhadas pela relação com o outro, pelos trejeitos e cacoetes de cada gente. Ainda que não, cada obra da chamada vanguarda modernista latinamericana diz dessas narrativas, traz, na tinta de escrever ou pintar, o tom rubro de cada litro dessa cor derramado (toneladas de plasma, hemácias, leucócitos e plaquetas).

Ceifar os corpos, ceifar o verso, romper com um padrão estilístico (ou descobri-lo), com uma fo(o)rma de figuração (ou descobri-la). A guerra que, das trincheiras majoritariamente urbanas, faz brotar o front (o chamado avant garde da Arte) o qual destrincha e despedaça uma determinada lógica, quebra as réguas de medição dum

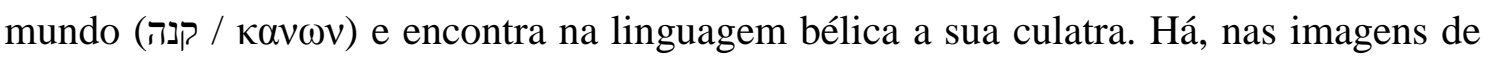
guerra (na América, a do Paraguai), um rebatimento que, de forma alegórica, metonímica, metafórica, retumba noutras figuras através de seu caráter simbólico e se

\footnotetext{
${ }^{1}$ Mestre em Artes Visuais, UFPel, e doutorando em Letras, UFRGS.
} 
faz arma verbo-voco-visual (para fazer ecoar a máxima concretista brasileira) de defesa, avesso de régua, sem vara de marmelo ou palmatória.

Para dizer das culatras bélicas encontradas, na língua, pelos poetas e demais artistas, a autora percorre um caminho discursivo que é engatilhado desde Maquiavel com sua Arte da Guerra, marcadamente no que podemos extrair de uma "linguagem da guerra" e então alveja as publicações mais recentes. Chamamos a atenção para a leitura que a autora faz da produção de John Keegan, sobretudo pelo teórico elencar o que seriam os três elementos entrincheirados com a guerra, intrínsecos ao seu fazer: elemento moral, intelectual e tecnológico. A partir de Keegan, a autora desfecha o pensamento proposto por Maquiavel (em A arte da Guerra) e atinge os conflitos temporalmente mais próximos de nós como, por exemplo, a Primeira e a Segunda Grande Guerra e as suas linguagens (da guerra), as suas sintaxes: os modos de matar, os modos de destruir, a relação com a política (e a sua política) e o seu fazer (guerra/política). Nesse sentido, podemos extrair uma espécie de "vontade de paz" de multiforme grafia e significado como pretexto para a guerra. Guerrear em nome de uma concepção de paz cuja tradução foi vertida por quem não fora alfabetizado nessa língua.

Para pensar essas questões, a autora ainda debruça-se sobre o pensamento de Carl von Clausewitz, recorrendo ao contraponto proposto por Michel Foucault, uma vez que, ao contrário de Clausewitz, Foucault propõe que a política é a continuação da guerra, e não o contrário. Para dar continuidade a essas questões, espessando ainda mais o discurso, a teórica recorre aos filósofos Gilles Deleuze e Felix Guattari, marcadamente quando a dupla se refere às relações entre a "máquina de guerra" e o Estado e entre "soberania política" e "potência política". Nesse sentido, a velocidade e o segredo da "máquina de guerra" são assegurados pelo braço maquínico e metálico do Estado, o qual patrocina determinadas "distinções", dentre as quais podemos salientar a permanência de termos proferidos com desprezo, como, por exemplo, "tribo" e/ou "raça”, vocábulos os quais são sempre expostos como "inferiores", porque minoritários e minoritários porque oprimidos, sendo uma característica o corolário da outra. Existem, pois, em nome de uma opressão que sofrem, uma vez que não é uma determinada concepção de "pureza" que define a raça, mas sim a "impureza" que o Sistema de Dominação lhe confere. Quanto a essas “impurezas”, salientadas por Deleuze e Guattari, espreitadas pela Die Frankfurter Schule, pelo Collège de Sociologie e sublinhadas em Guerra e Poesia pela 
teórica, podemos frisar as arapucas discursivas disseminadas pelo Estado para incriminar determinados gestos, recriminar determinados corpos. Recordemos os cenários de desilusão, os jogos de poder, a violência física e a agressão moral, disseminados por hecatombes como a Primeira Grande Guerra e, lembrados por Walter Benjamin em textos como "Experiência e Pobreza", em que, num tom pesaroso, o filósofo aponta para a pobreza (Armut) dos homens que, após a guerra, retornam para casa falidos e amputados não apenas da capacidade de narrar, como da possibilidade de experienciar algo narrável. Talvez essa tivesse sido a vontade do homem: não ter com o que/quem aprender, nem ter o que narrar: eis que cai sobre a campa da fala a última pá de terra.

De volta à Latinamérica (sem, necessariamente, termos saído dela), atentemos para o batalhão de artistas/pensadores composto por Ronald de Carvalho, Oliverio Girondo, Raul Bopp, Murilo Mendes, Manuel Bandeira, Joaquim Cardozo, Jorge Luis Borges, Guilhermo Juan, Xul Solar, sobre o qual a autora se debruça. Lugar esse (Latinamérica) que é representado em Guerra e Poesia como um corpo único e translinguístico, um dos claros espaços conceituais remanescentes da Pangeia, lugar que faz de cada língua um esqueleto de guarda-chuva aberto num temporal babélico, espaço poético que faz, da língua e suas cercanias idiomáticas, uma arma contra a belicosidade do Estado. Arma essa que pode estar travestida num conjunto de cenas emblemáticas, construídas, seja por poetas, seja por artistas plásticos que recorrem às manifestações populares e seus cantos, composições em verso que dialogam com cantigas infantis e outros gêneros lúdicos que, enquanto dialogam, elevam um discurso transcultural e interétnico, (o neocriollo, no caso de Xul Solar). Nesse sentido, chamemos a atenção para os "sambas guerreiros" estudados pela teórica no segundo capítulo (“Ouvir a Voz Popular") do livro. No lado brasileiro da tríplice, a guerra fez reascender um discurso principalmente étnico, fala a qual reforça a presença, sobretudo negra (e indígena) entre os voluntários da pátria, voluntários forçados, violentados nela, mortos por ela. No terceiro capítulo ("Falar a Identidade Modernista”), a autora apontará para essas questões, focalizando os aspectos da identidade modernista a partir de três pontos: "espacial", desde a produção de Ronald de Carvalho e Oliverio Girondo; "temporal", desde Raul Bopp, Murilo Mendes, Manuel Bandeira, Joaquim Cardozo e, "na linguagem", a partir de Murilo Mendes, Oliverio Girondo, Jorge Luis Borges e Guilhermo Juan, e Xul Solar. Neste 
último ponto, a autora irá comentar que, "pela incorporação do popular e pelas transformações ocasionadas por acréscimos e supressões de vogais e consoantes, adequando-se ao uso da língua espanhola, oral e fora do centro, [a linguagem] participa do arsenal modernista que se opõe às formas poéticas letradas e metropolitanas." (BITTENCOURT, 2014, 125). Já que mencionamos aqui as línguas e os corpos mesclados, mestiços e transnacionais, chamemos também a atenção para o quarto capítulo do livro ("Ver os Projetos de Nação"), lugar em que a autora se debruça sobre as questões do corpo nacional e do transnacional, tendo, como exemplares e pontos de partida, principalmente, as aquarelas e a literatura de Oliverio Girondo e Xul Solar e as pinturas a óleo de Alberto da Veiga Guignard e Tarsila do Amaral, pensadora e pensadores fundamentais para refletirmos a respeito da hibridez das formas e das linguagens e ainda, a própria noção de apagamento das fronteiras, questão cara a determinados pensadores, sobretudo os citados. No caso específico da pintura, a autora compara trabalhos como as pinturas "País" e "Milícia", produzidas em 1925 por Xul Solar e "A Família do Fuzileiro Naval", confeccionada cinco anos depois por Alberto da Veiga Guignard, obras que, por mais que trabalhem as questões plásticas ou que preservem certa ingenuidade, podem ser lidas como trabalhos extremamente críticos e voltados às temáticas da guerra e da nacionalidade, sobretudo a pintura de Guignard.

Nesse sentido, já que é trazida também a produção plástica em comparação com a literária, podemos não apenas entender a caneta como uma arma, assim como perceber a linguagem pictórica como um artefato pontiagudo capaz de rasgar os discursos e adentrar as entranhas de um determinado organismo ou sistema de dominação. Já que aludimos a esses artefatos, no quinto capítulo ("Dispositivos Bélico-Poéticos") a autora se inclina sobre a relação dos pensadores Carybé e Mario de Andrade com a linguagem e as mitologias locais, com a construção de cada universo mestiço e que, ao desenvolver cada espaço, os escritores criam também armas para uma guerra ou guerrilha específica, artefatos que a teórica chamou de "dispositivos bélico-poéticos".

No sexto capítulo (“Antologia da Guerra”) é exposta a produção mencionada ao longo do livro, seja a literatura de Xul Solar, trecho de uma carta de Mario de Andrade a Augusto Meyer, os poemas de Jorge de Lima, Ascenso Ferreira, Ronald de Carvalho, Oliverio Girondo, Raul Bopp, Murilo Mendes, Manuel Bandeira, Joaquim Cardozo, Jorge Luis Borges e Guilhermo Juan, seja a produção plástica de Alberto da Veiga 
Guignard, Xul Solar, Oliverio Girondo, Tarsila do Amaral e Carybé. Uma legítima coleção de armas, polemofilia. É com esses dispositivos bélico-poéticos do modernismo que a autora encerra sua brilhante Guerra e Poesia, livro o qual nos oferece uma precisa leitura dos primeiros estilhaços e faíscas proferidos pelos artistas-escritores do modernismo latinamericano. 